\title{
Retrospective Photogrammetry in Greek Archaeology
}

\author{
COLIN WALLACE \\ University of Waterloo, ON, Canada
}

\begin{abstract}
This paper addresses the advantages as well as the obstacles in practicing photogrammetry based on archival photos of archaeological sites and examines how the results can be put to use for further research, preservation, restoration and monitoring rates of deterioration. While the extensive use of historic aerial photographs has been applied to photogrammetric modeling, archaeological excavation archives have been largely ignored. Historically, archaeological excavations have been vigorosly documented photographically and many of these photographs are available in archives. Not all photo archives, however, are suitable for photogrammetry, as they were not produced with the intention of overlap and other photogrammetric qualities. By selectively choosing photographs with common points and manipulating exposures, cropping and other properties to enhance commonality, 3D models of past structures and excavations can allow us to revisit them, produce accurate measurements and view angles that were never photographed. Employing this methodology for sites that are still accessible provides the opportunity for quantitative comparison of the current condition of the site to the condition at the time of excavation. Used in this way, retrospective photogrammetry will have impacts in the preservation, restoration and monitoring of the deterioration of archaeological sites. Examples from the Athenian Agora: the State Prison and Omega House, and Ancient Corinth: the Fountain of the Lamps will be used to demonstrate these possibilities.
\end{abstract}

Key words:

Retrospective Photogrammetry, Photogrammetry, 3D Modeling, Archival Photographs, Archaeology

SDH Reference:

Colin Wallace 2017. Retrospective Photogrammetry in Greek Archaeology. SDH, 1, 2, 607-626.

DOI : $10.14434 /$ sdh.v1i2.23251

\section{INTRODUCTION}

Archaeological practice requires monuments, structures, sites, artefacts and organic remains to be carefully examined, recorded, studied, conserved and, when needed, restored. Artefacts and any organic remains, while having been recorded in situ, are necessarily removed from their context. Their documentation imposes the recording of location, form and dimensions. This constitutes a necessary part of all fieldwork and museum work, using, in each case, the optimal methodology and equipment, depending on the type of measurements, the scale of the final product, the size, the complexity of the object and the budget available [Moysiadis and Perakis 2011]."

In the past decade, the use of "close-range photogrammetry [CRP, also known as structure from motion (SfM)]" [Opitz and Limp 2015] to produce 3D models of archaeological sites and excavations

Author's address: Colin Wallace, Department of Geography, University of Waterloo, 200 University Ave W Waterloo, ON, Canada; N2L 3G1 email: colin@uwaterloo.ca

Permission to make digital or hardcopies of part or all of this work is granted without fee according to the open access policy of SDH.

(c) 2017 SDH Open Access Journal

Studies in Digital Heritage, Vol. 1, No. 2, Publication date: December 2017 
has seen rapid growth and acceptance due to a significant reduction in cost and labour. It now "constitutes a powerful textured representation ... where the vectorised interpretation ... is left to the corresponding specialists" (archaeologists, architects, conservators, engineers etc.) [Moullou and Mavromati 2007]. It has become commonplace in archaeological excavations (and in some cases required in permits) to use CRP to produce a three-dimensional record. In current archaeological practice, photogrammetry is being used not only to record the final result of excavation but also the stages leading to it, allowing later re-examination of details that might not have been observed during the excavation due to natural human biases.

While this bodes well for accurate modeling being available in the future, past excavations could benefit from a similar treatment. In reference to contemporary use of 3D modeling technologies, Powlesland [2014] states that "the importance of the technique is best appreciated by the number of colleagues who, when they engage with the method for the first time, simply respond with 'if only we had this when we excavated at...'."

Archaeological research has a long history of requiring comprehensive photographic documentation and, in many cases, the photographs have significant overlap, enabling their use in photogrammetry to produce 3D models. Some were taken with the intention of using photogrammetry to create topographic maps and site plans. Now, with the use of those maps and plans, we can reverse the procedure to georeference the photographs in order to create properly textured three-dimensional models.

\section{WHAT IS RETROSPECTIVE PHOTOGRAMMETRY?}

Photographic documentation of previously excavated sites has not been sufficiently exploited as a source of new, unexamined data. Retrospective photogrammetry is a novel approach of producing fully functional three-dimensional models using archival photographs, plans and drawings. Photographs taken at the time of excavation are static and while informative, hold little quantifiable data. When multiple overlapping images were taken, this provides an opportunity for the photogrammetrist to produce three-dimensional models of qualities ranging from an interesting ability to view a site from a different perspective to the ability to measure and quantify a site as it was when it was first excavated.

\section{OBJECTIVES}

Fortunately, the thoroughness of archaeologists in documenting their sites has often resulted in rich archives of photographs that can continue to be useful in the research of those sites. In this paper, I outline not only how appropriate archival photos can be used in photogrammetry but additionally, how photographs that are not appropriate candidates can also be used to create 3D imagery of past excavations. The Hellenic Ministry of Culture and Sports and The American School of Classical Studies in Athens have produced a significant digital archive of photographs, drawings, plans and notebooks from throughout the American School's history of excavation in Greece. While these resources are valuable in their current form, the new data that can be produced from them will allow us to revisit these sites and compare them to models based on their current condition. In any given 
location, ten archival photographs constitute a finite set of viewpoints. With successful photogrammetric 3D modeling, those ten photographs can result in unlimited numbers of views from whatever angle the viewer chooses, allowing one to see the site as it was at the time of excavation more fully.

Photogrammetry can also be employed for photographic documentation of progressive excavation conducted in the past. When archaeologists work through layer upon layer of strata, they must make discretionary decisions based only on what has been found so far. They then must decide what stays, what is removed and what is backfilled. If the archival photographs have sufficient photographic coverage of the excavation process, it is possible to build models of multiple layers of strata as they were excavated, and to re-examine the decision processes made at the time of excavation.

The primary objective in constructing these models is using them to work towards the preservation and conservation of previously-excavated sites as well as using them to demonstrate how newly excavated sites need to be immediately preserved. Additionally, using archival materials in 3D modeling allows researchers to revisit sites which may have deteriorated or have been backfilled or destroyed. The 3D model provides the opportunity to study the site anew and the ability to measure, quantify and even virtually reconstruct it in order to maximize the amount of information gleaned from the efforts of so long ago.

\section{METHODOLOGY}

The inspiration behind this method stems from a visit to an archaeological site, the Fountain of the Lamps, in Ancient Corinth in 2012, and the subsequent viewing of a collection of photographs taken during the excavation (in the '60s and '70s) which highlighted just how much damage time, weather and vegetation could wreak on a site once it was exposed (Figure 1). There was a possibility that by producing a 3D model using the older photographs, it could be compared to a newer model allowing an accurate assessment of deterioration. The area is a marble Roman swimming pool dubbed "The Fountain of the Lamps" and is part of a larger fountain-bath complex erected and refurbished during the Hellenistic and Early Roman periods [Garnett 1975]. Excavated between 1968 and 1972 by James Wiseman, the Fountain of the Lamps was extensively photographed during the project, with many photographs having enough overlap to be used in photogrammetry to reconstruct the site as a 3D model. Experiments using the photographs in Agisoft Photoscan produced limited but promising results and led to the implementation of several unconventional techniques in order to improve those results. Current results are based on existing scans of archival photographs. Future projects within this area could benefit from new scans of original negatives and photo-plates at higher resolutions (pending new permissions), whereas current work is utilizing existing scan data of unknown origin (negative or print). Scanning from negatives should significantly reduce grain and enhance results. When scanning, a high, consistent resolution should be used. All photographs used for models in this paper were from a digital archive and the author did not have access to the original photographs to control or increase resolution. Resolutions ranged from $96 \mathrm{dpi}$ to $4000 \mathrm{dpi}$.

Similar projects in the Athenian Agora, involving structures that are known as the State Prison and Omega House, have yielded positive results using the methods developed with work on the Fountain of the Lamps. The Omega House, also known as House C, is a large, late Roman structure dating from 
the fourth to sixth centuries A.D. on the slopes of the Areopagus hill in the Athenian Agora. The building's 30 rooms included ornate mosaics, tilework, elaborate water installations, a nymphaeum and two or three peristyle courtyards according to some scholars. It is thought to have been one of the last philosophical schools of Athens. Omega House was excavated from 1969 to 1971 by John Camp. It has remained largely exposed to the elements since then, resulting in noticeable natural deterioration. The State Prison is a long rectangular building in the southwest Agora, where "[i]t has been suggested that this might be the State Prison (desmoterion), where Sokrates and others convicted of political crimes were executed." [Camp 2003]

The following sections will outline the problems involved in retrospective photogrammetry and the innovative (unconventional) methods required to produce satisfactory results in archival 3D modeling. Most important in the process is starting out with a clear idea of what result is sought; what features are important and how the model will be used. Moullou and Mavromati [2007] find that "the end product must be clearly specified a priori, according to strictly defined needs. It is only then that the pursued results will be accomplished."

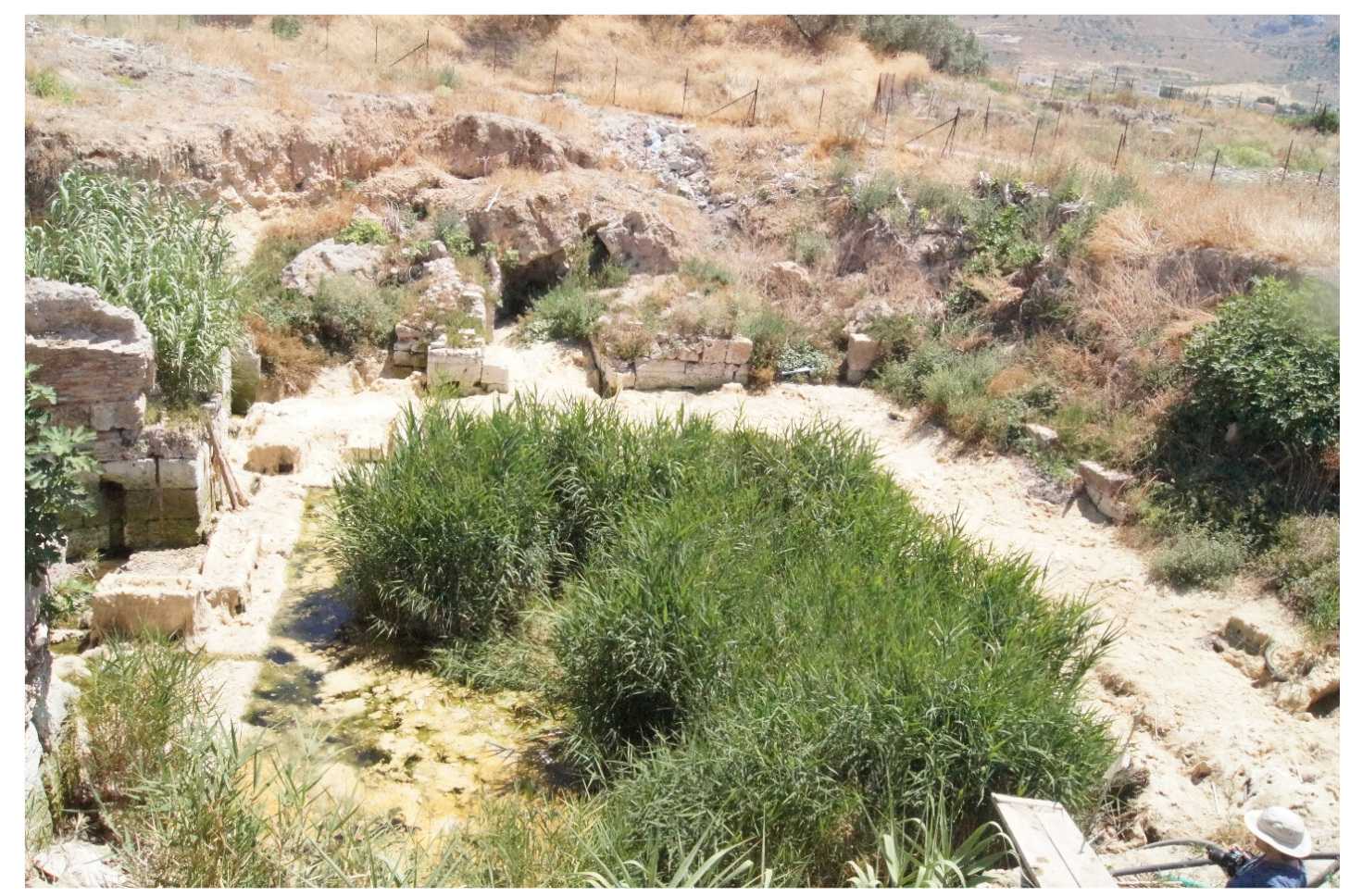

Figure 1. Fountain of the Lamps, Ancient Corinth, Greece, 2012.

\subsection{Problems}

While retrospective photogrammetry uses the same basic processes as contemporary CRP, it also involves using a number of different approaches in order to achieve results. Archival photographs used in the retrospective method were not usually intended for this purpose or, if they were intended 
for analytical photogrammetry, their numbers are too few. When a site has been photographically documented with overlap between each picture and that documentation contiguously covers the entire site, positive results will be achieved. If there is overlap between photographs but not contiguous coverage, portions of the site and its structures can still be reconstructed. It should be noted that gaps in photographic coverage, although regrettable, might be areas of less significance in the view of the original documenting archaeologist. On initial inspection of a data set, there may seem to be a promise of good overlap and sufficient documentation but if there was too great a range of cameras and focal lengths used, modeling proves less successful. Conversely, in some data sets that look less promising in their comprehensiveness and overlap, successful results can be achieved because one or few different cameras were used.

Camera calibration, an accepted part of the contemporary photogrammetric process, is not possible with archival photos, as most of them have no record of what kind of camera or lens was used. There does not seem to be a way around this problem, although, as will be discussed, introducing some contemporary photographs with calibration can enhance accuracy. The following are some of the more common problems encountered when working with archival photographs. While some of these problems also occur with contemporary photogrammetry, they are compounded by the inappropriateness of the archival photos, lack of georeferencing and the absence of photographic metadata.

\subsubsection{Duplicate or Similar Photos}

While the workflow is similar to that of contemporary photogrammetry [Wallace 2016], conventional methods, as applied using Agisoft Photoscan, do not always apply when working with archival photographs. If, for example, the model is using thirty photos with insufficient overlap and two or three photographs have significant overlap, the software will attempt to make a model of those three and ignore all other photographs. By removing one or two of the overly similar photographs, the software is then able to process the others based on their similarities. Including reference points can lead the software to include new, less similar photos but when two are virtual twins, the results are thwarted. Figure $2 \mathrm{a}$ and $\mathrm{b}$ prevented the modeling of the Omega House Nymphaeum until the latter was removed. The problem of similar or identical photographs is quite common in archival collections because over time negatives can be used to produce multiple prints with different cropping, exposure and labelling, making them appear to be different images. In addition, when film was used to document sites, "blocking" exposures by taking multiple shots at different exposure settings produced similar but not necessarily identical photographs. 


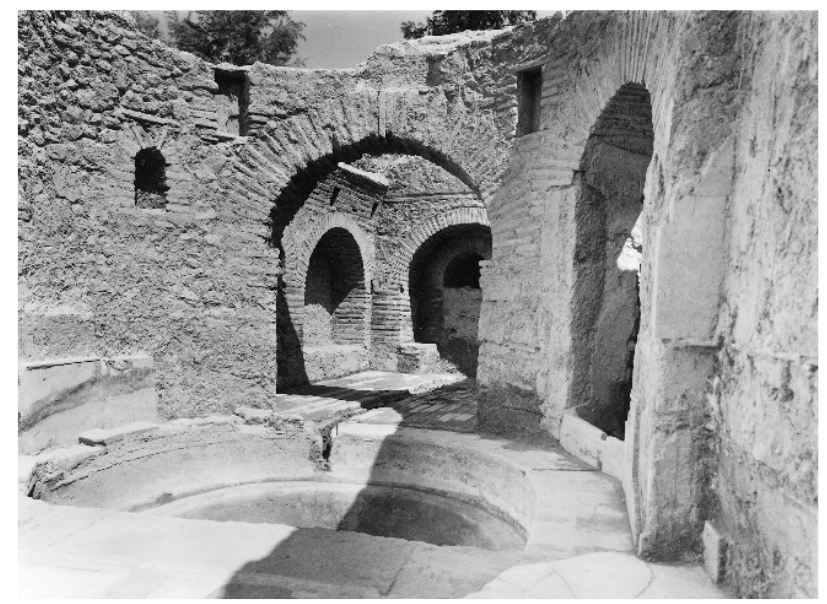

a)

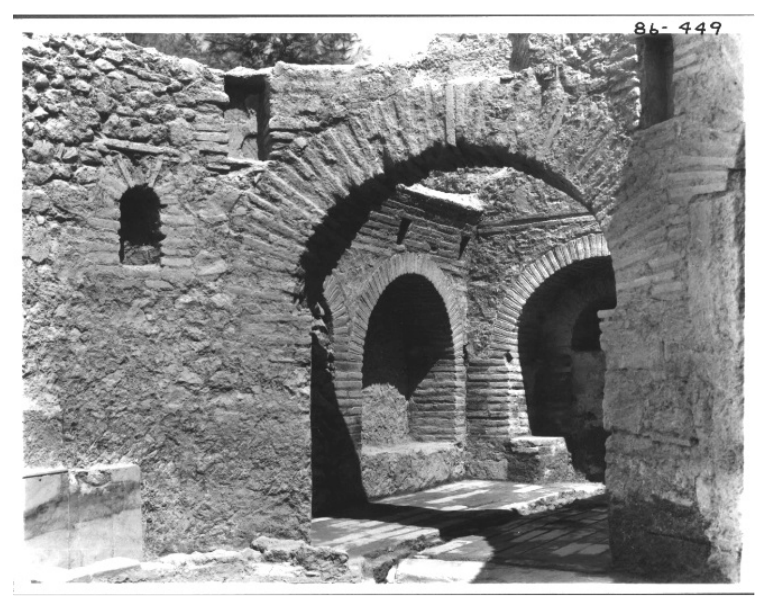

b)

Figure 2 a) and b): two overly similar images of Nymphaeum, Omega House, Athenian Agora.

\subsubsection{Flat Plane Models and Unidirectional photographs}

Using a set of photographs that are primarily taken from one direction can result in what at first seems like a 3D model but upon rotation reveals itself to be a flat or slightly curved panel. In their mapping of dinosaur tracks using archival photographs, Falkingham et al. [2014] note that "the fact that the photographs were all taken from a roughly south facing direction meant that parts of the resulting model, particularly at the northern end, are severely lacking in detail." Even if there is a large assortment of photographs from other angles, a disproportionate number from one perspective can cause this problem and sometimes the best solution is to remove one or two of that group. Figure 3 illustrates the type of limited perspective in photographs that can produce a flat plane model while Figure 4 illustrates show the resulting model.

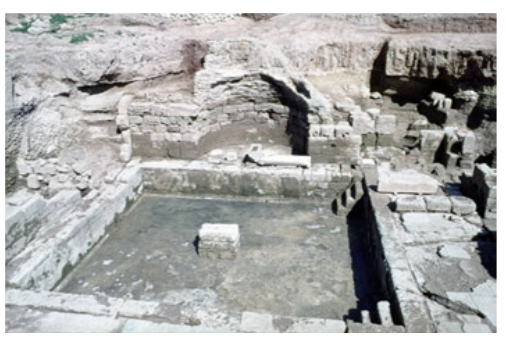

a)

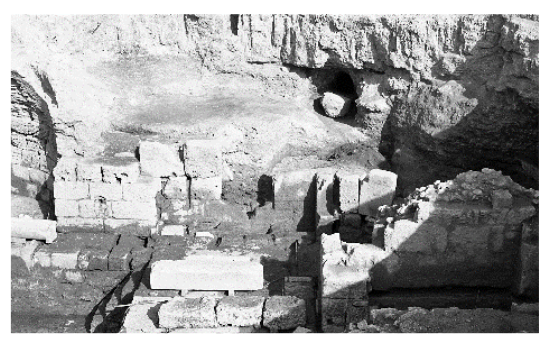

b)

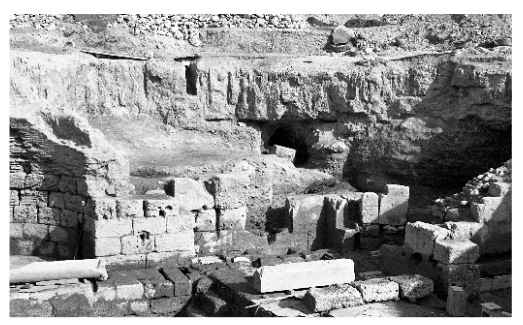

c)

Figure 3. Three analyzed photographs of Fountain of the Lamps $(a, b$ and $c)$ that have resulted in flat plane modeling. 


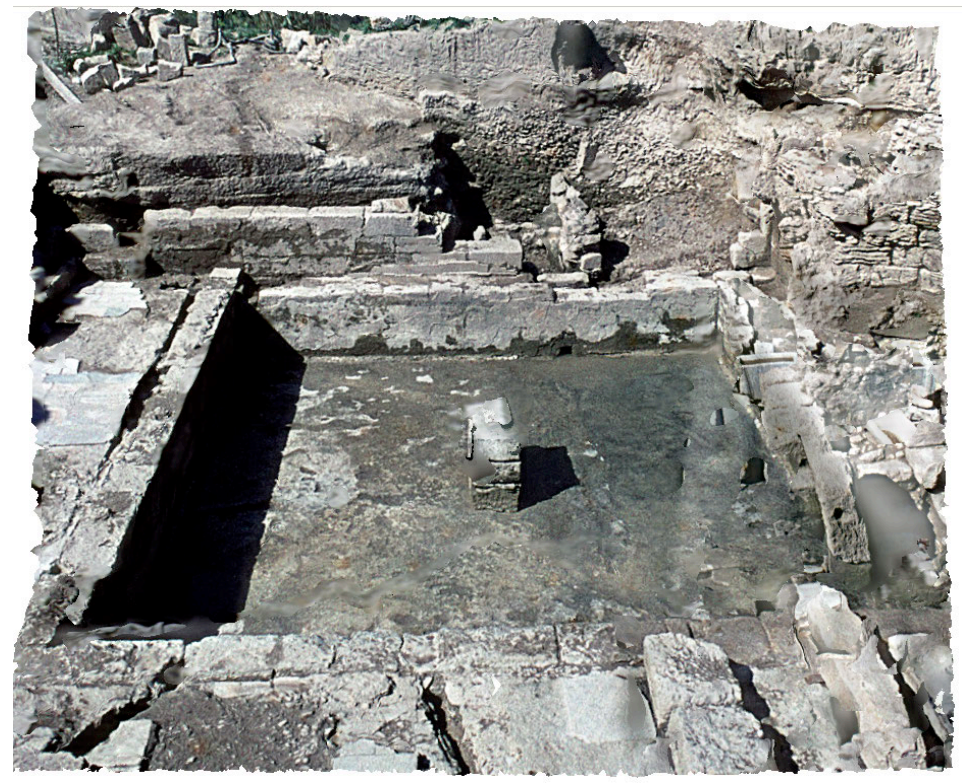

a)

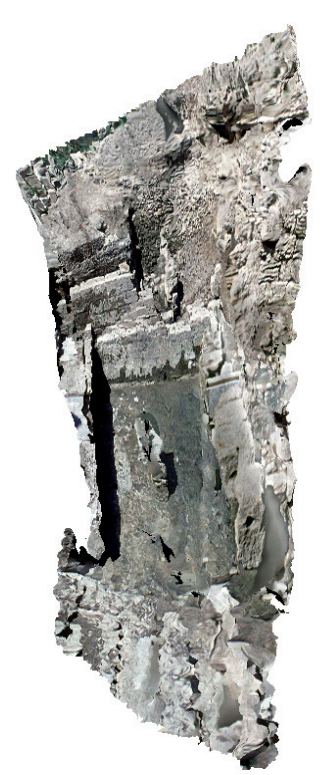

b)

Figure 4. Another flat plane point model: a) result of unidirectional photographs; b) what only slight rotation reveals.

\subsubsection{Problem Photos}

When engaging in retrospective photogrammetry there is an unusual phenomenon that occurs. Occasionally a photo completely dismantles the entire model. Whether it is from a different camera with different distortion or some other factor remains to be determined.

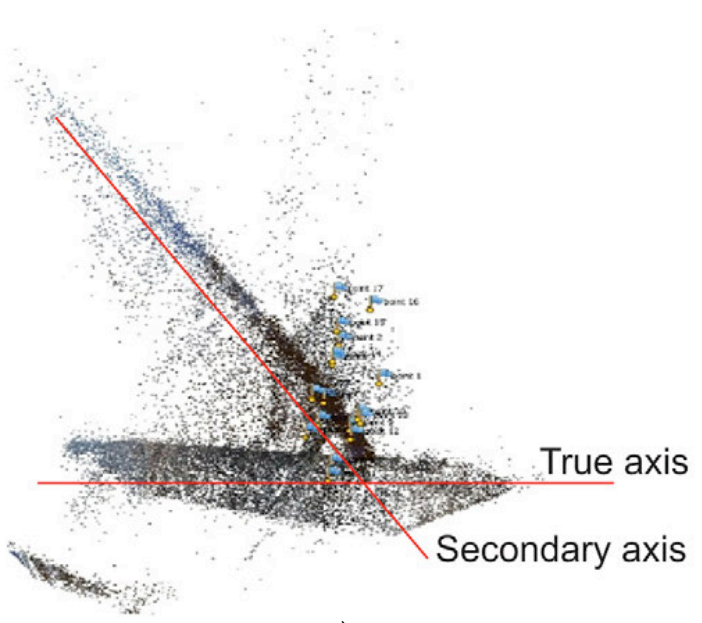

a)

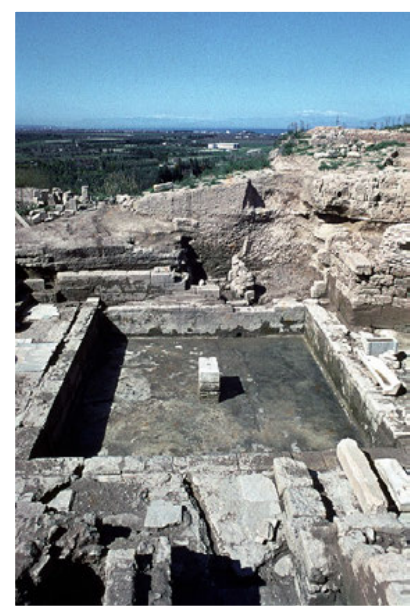

b)

Figure 5. a) Multiple axis conflicts occur as a seemingly normal photograph (b) creates secondary modeling. The secondary point cloud is seen rising upwards. 
Once removed, the rest of the model will come together with ease; however, it is often difficult to determine which photo is at fault. In Figure $5 \mathrm{a}$ the effect produced by the problem photo (Figure 5b) is evident.

\subsubsection{Marker Spacing}

Sometimes due to the disparity in the quality and dissimilarity in the look, size, and resolution of photos, in some instances, a group of promising photographs can be assembled only to have the software find no commonality in them and no model is produced. By inserting reference points on features that are common in multiple photographs, these photographs can be unified. This is why Agisoft Photoscan has proven to be the tool best suited for this process. Other software, such as VisualSFM, while able to import georeferences, does not allow the insertion of arbitrary points. Autodesk's now-cancelled 123D Catch did allow manual insertion of points but the process was time consuming and the results not as successful as Photoscan. Autodesk's replacement for 123D Catch, Regard 3D, is unable to match photographs if a focal length is not known. There are pitfalls in using manual reference points, however, requiring that the points be strategically placed. First, it is important to choose points with the maximum visibility in multiple photographs. A common point in only two photographs will do little to unify a project, whereas several photographs sharing common points are often instantly viable. A minimum of three markers is needed to cause an ignored photograph to be included in a model, and while an increase in the number of markers can enhance a model, too many can result in some whose closeness creates a higher level of error.

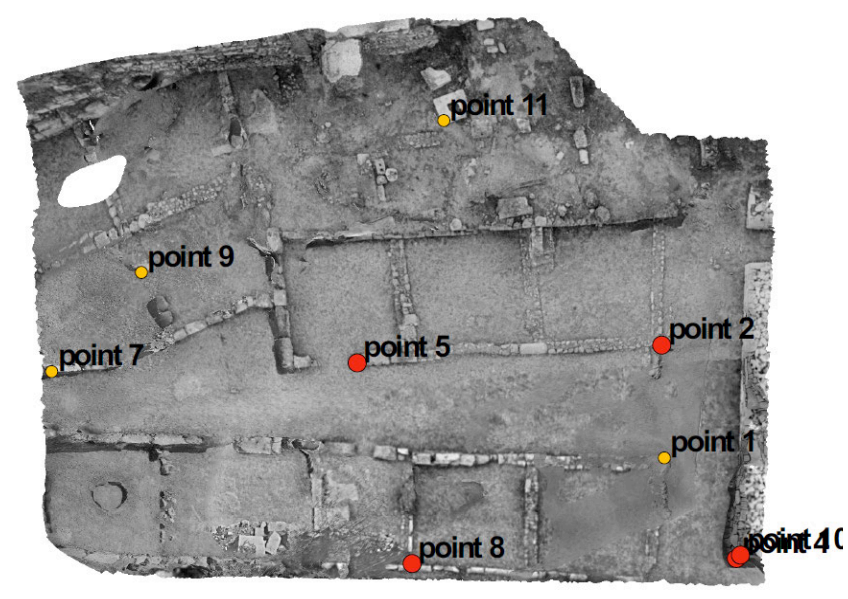

a)

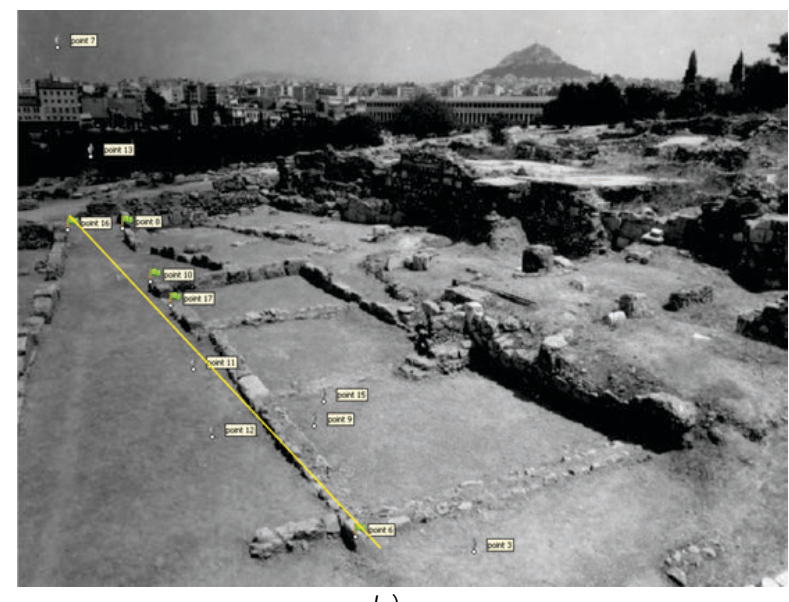

b)

Figure 6. Manual reference points using broad spacing and variable heights (a) in the State Prison eliminated distortion caused by closely aligned points (b), which result in inappropriate point placement suggestions, as is seen in the figure.

In some cases, visible points may be too close together or follow a particular path (Figure 6b). In such cases, a portion of the model can pivot on its axis, creating two conjoined models on different planes, as shown in Figure 7a. By spreading reference points out and ensuring that they consist of the widest 
possible variety on $\mathrm{X}, \mathrm{Y}$ and $\mathrm{Z}$ axes, a preferable result, as shown in Figure $7 \mathrm{~b}$, will be produced. While it would be preferable to say that placing points is a formulaic process, experience gained through many attempts helps the user to visually assess which points are going to create the most voluminous three-dimensional spaces between them, leading to better results.

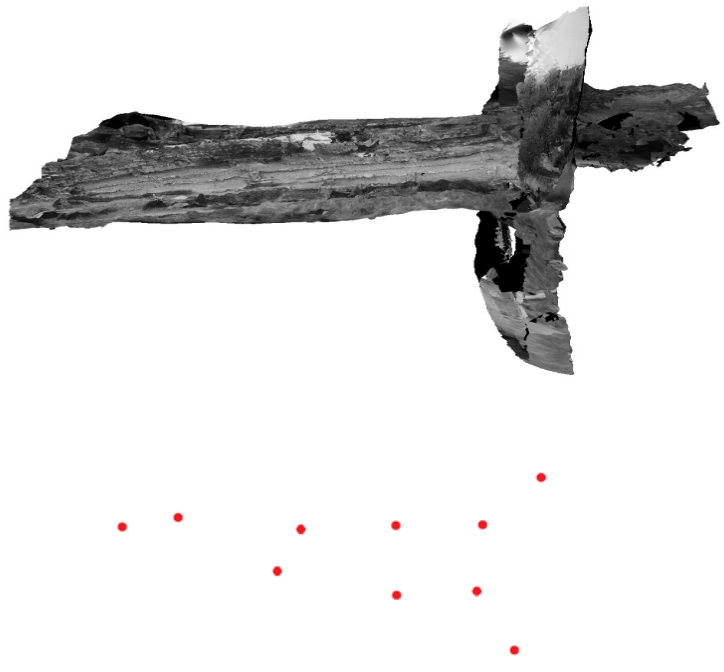

a)

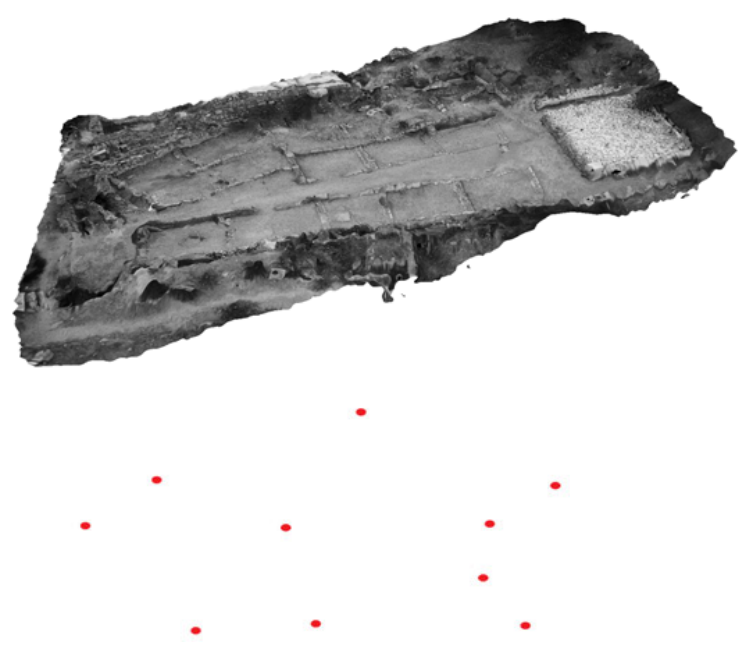

b)

Figure 7. State Prison, Athenian Agora: a) reconstruction with closely spaced reference points; b) reconstruction with widely, evenly spaced reference points.

\subsubsection{Grain on Top of Pixels}

When producing contemporary photogrammetry using photographs produced by DSLR cameras, the randomness of pixels is an accepted limitation. When working with archival photographs, however, this problem is compounded, as there is also the grain of the film, the grain of the print and the pixels of the scan which together can make the same point in two photos look significantly different and prevent the software from recognizing their similarity. One solution is to scan directly from the original negatives or photo plates whenever possible. The examples in Figure 8 show how, in two similar photo prints scanned at 1350 dpi resolution, these differences can affect what the software is seeing. 


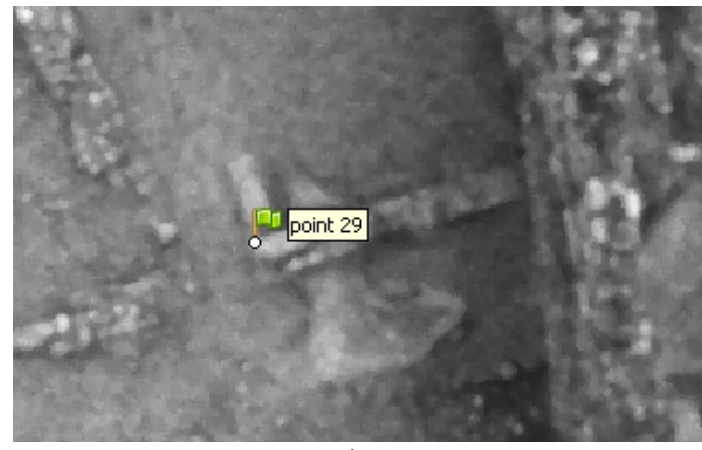

a)

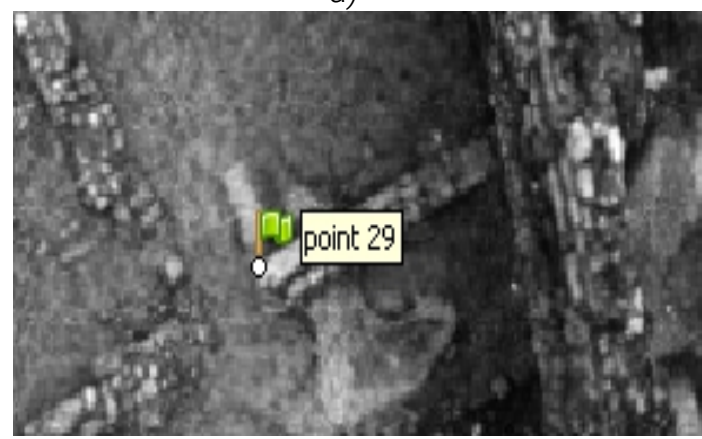

c)

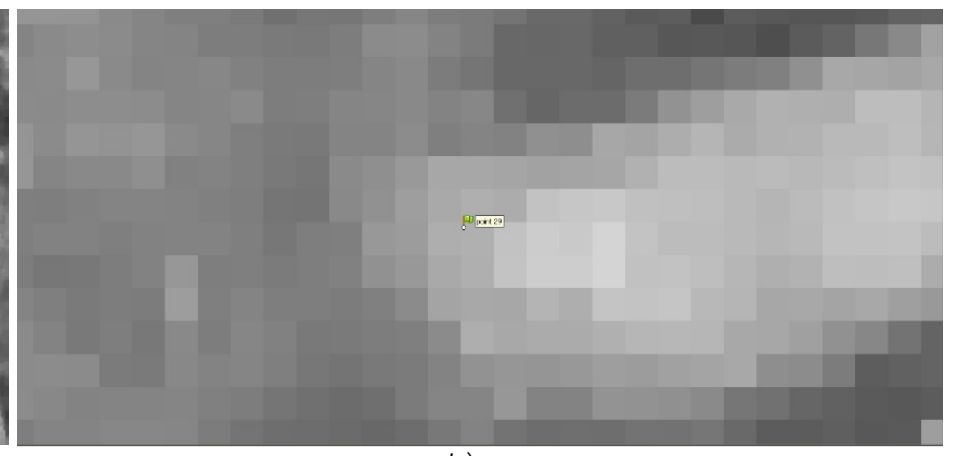

b)

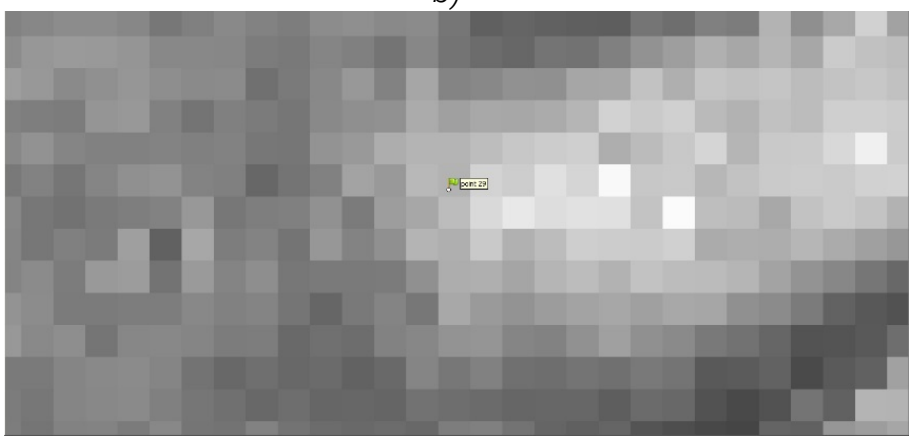

d)

Figure 8. Similar 1350 dpi photographs $(a, c)$ and the effect of pixels and grain on recognition $(b, d)$.

\subsection{Unconventional Methods}

\subsubsection{Including Contemporary Photos}

During construction of 3D models, gaps due to the lack of overlapping photographs can lead to incomplete or even failed models. On sites where structures and features remain relatively intact, contemporary photographs can be converted to black and white with similar gray scales and incorporated into the model building process in order to fill those gaps. In Figure 9a, a contemporary photograph of the apsidal structure in Omega house has been processed to give it similar qualities to the archival photographs such as Figure 9b. While the walls in the contemporary photo have deteriorated, their geometries remain intact, allowing their use in the cohesion of the model. Once the mesh (an interconnected set of triangles joining three three-dimensional points at a time) has been created using all photographs, the modern photographs can be disabled. This allows texturing of the model only using the archival photographs. In Figure 10a the disabling of modern photographs has resulted in the original smooth marble and plaster surfaces being applied to the entire model, while Figure 10b shows what the model would look like if the entire set of photographs was enabled, resulting in a mismatch of smooth and coarse surfaces. Prior to adding the contemporary photographs there was not enough overlap to produce a cohesive model. Introducing contemporary photographs when the condition of the structure has retained its basic geometry significantly enhances the viability of the modeling. One reason why this method not only works but also is necessary is that photogrammetry is more difficult when modeling smooth, pale surfaces such as 
marble and plaster. The flaws in the contemporary photographs are better able to bind the images together. While including large areas of contemporary photographs would negate the quantifiable uses of the model, this method can be used where little change has happened visually or where the resulting contemporary modeled aspects would have resulted in a gap anyway. The method has only been attempted so far with the Omega house and further experimentation is warranted.

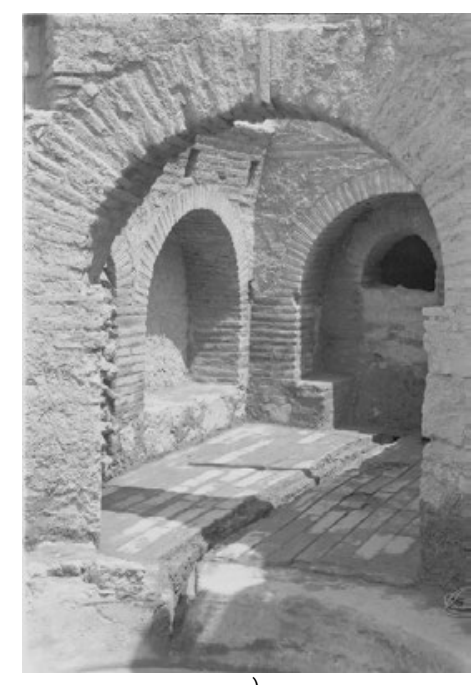

a)

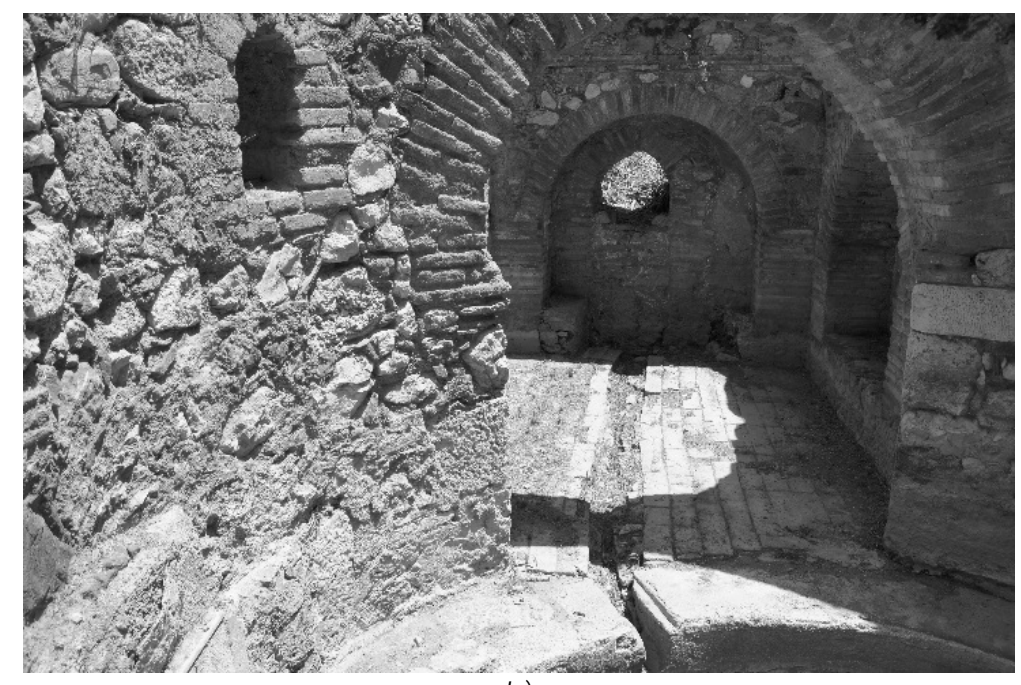

b)

Figure 9. a) Modern photograph converted to B\&W for use in the model; b) original excavation photo.

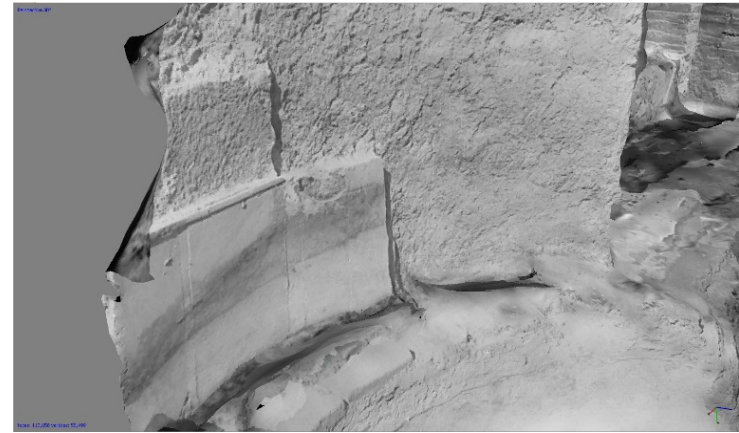

a)

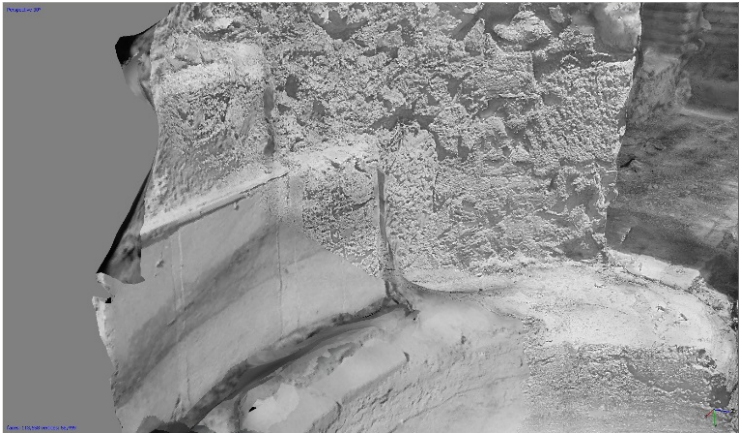

b)

Figure 10. Differently textured models: a) hybrid model with modern photographs disabled; b) textured model with old and new photographs enabled.

\subsubsection{Site plans instead of aerial photographs or survey data}

Aerial photographs included in modeling can significantly enhance the accuracy of the 3D model. Fortunately, a number of Greek sites excavated in the late 1960s and early 1970s were documented using aerial photographs. For instances where they were not taken, an unconventional method has resulted in considerable success. Including site plans (georeferencing/surveying when available) as 
a regular, undistorted "image" in many cases helps to align the other disparate images for a more accurate model. Although the intention is to disable the site plan before textures are applied, leaving it enabled can also be used to comparatively view the modeling results and visually assess the accuracy, as can be seen in Figure 11. In a similar technique, Moore and Briggs [2002] compensate for a lack of orthorectification in their archival aerial photos by rectifying "the 1953 photographs ... to the 1994 orthophoto mosaic by selecting a series of between six and nine well-distributed, high-quality control points from the 1994 photos for each historical image."

In addition to the lack of distortion in the site plan (or elevations in the case of standing structures), the drawing can be scaled in programs such as AutoCAD or CorelDraw and with an XY origin set at the bottom left corner of the drawing, local coordinates can be determined for points within the model. Doing so allows the modeler to check other measurements on the model and confirm that there is consistency in the accuracy of the modeling. Additionally, if part of a structure was documented in floorplans and elevations but another part was not, this georeferencing can allow the modeler to reconstruct the dimensions and measurements of the undocumented portion. One caveat of note with elevations is that they should be of relatively flat surfaces. If they orthographically represent different depths of the structure, their lack of three-dimensional perspective will have an adverse effect on the software's ability to calculate parallaxes.

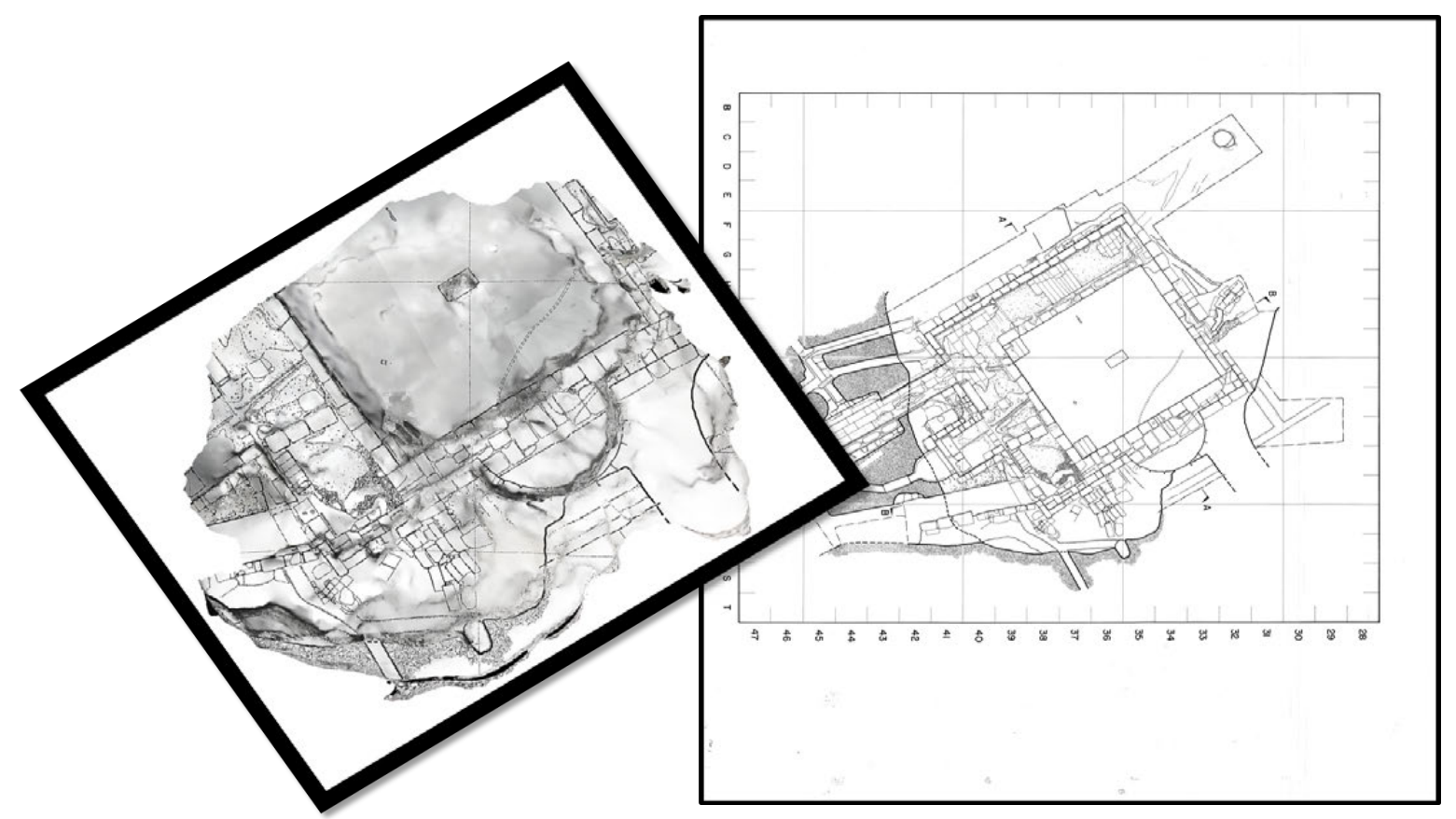

Figure 11. Site plan incorporated into model to improve alignment and verify result accuracy. In the figure on the left, the model's orthographic view is overlapped with the site plan, allowing visual confirmation of positive and negative results. 


\subsubsection{Using Rejected Photographs}

Ultimately, the preferable scenario for creating a 3D model is to acquire a large set of photographs taken at the same time with the same camera under the same lighting conditions. When searching through archives, some photographs taken under different conditions and at different times can seem unsuitable for the set being used and can be prematurely dismissed. Figure 12a shows a portion of Omega House in the Athenian Agora after its excavation, while Figure $12 b$ shows a similar scene while excavation was underway with exposed trenches, which can be masked during modeling.

In some cases, there is enough commonality in the photograph to retain it for applying textures by masking elements that are not contiguous. Occasionally one photograph will be cleared, while another similar photo may have workers, buckets, shovels etc. These can be masked so that not only the geometry can be employed but also the common photographic elements. Every piece of photographic documentation must be used to its fullest. In cases where one element is occasionally obscured, the combination of unobscured photos will create a proper image.

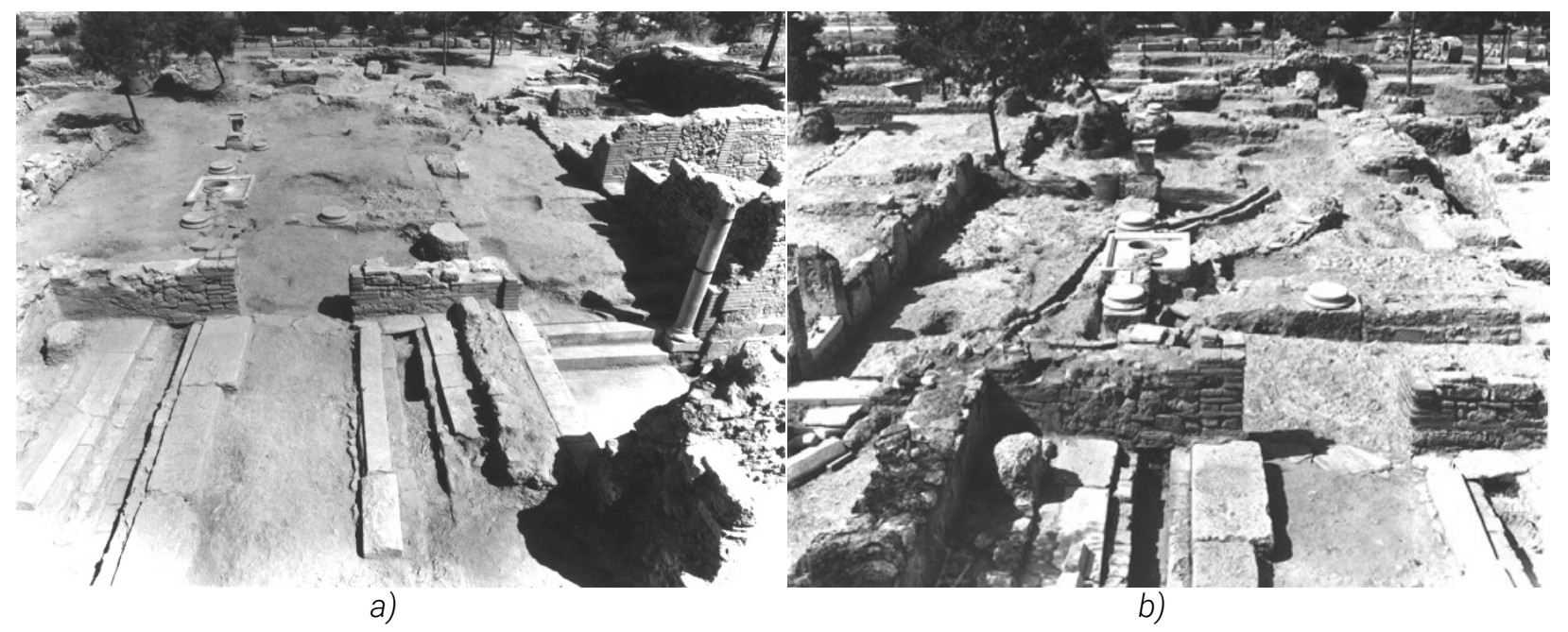

Figure 12. Omega House: a) post-excavation after backfilling and cleanup; b) during excavation.

\section{RESULTS}

Results so far have been very promising. First, just being able to achieve enough of a connection between photos to produce models has been shown to work. Even without georeferencing, the ability to manipulate models enough to determine where certain features were an achievement.

Further encouraging progress was made by showing that margins of error could be significantly reduced with the use of site plans, control points and even very vague GPS values taken from Google Earth. For example, in modeling the Fountain of the Lamps as it was in 1972, the addition of a site plan reduced the overall error in pixels from 139.824 to 30.011. Similar gains in accuracy have been achieved using rough GPS values in sites with features that are easily visible on Google Earth. Accurate measurements of the control points used in the Fountain of the Lamps are unavailable and 
the site is currently inaccessible for surveying, so no measure of accuracy in meters is available. Errors in pixels are used only to monitor incremental improvements during the modeling process.

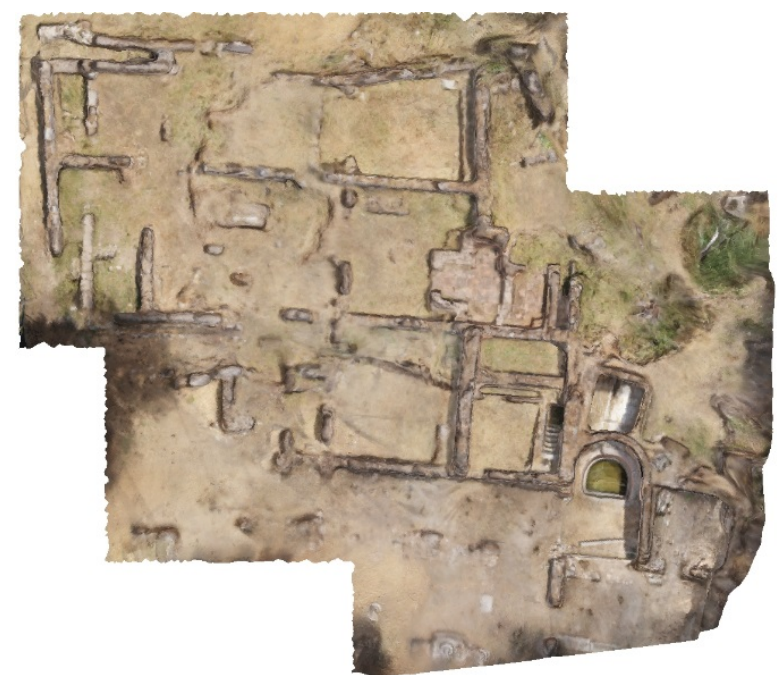

a)

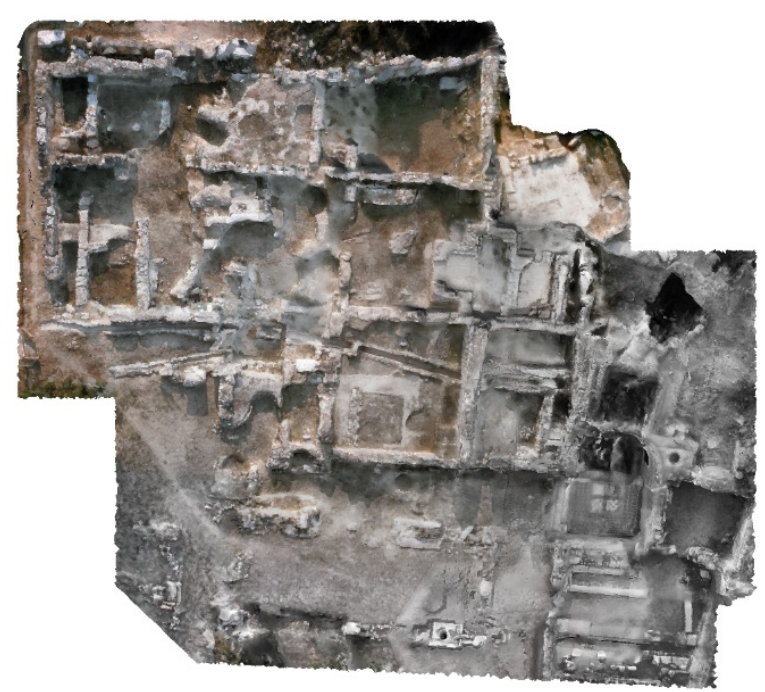

b)

Figure 13. Omega House, Athenian Agora, Athens: a) 3D modeling of the site in 2016; b) 3D modeling based on photographs taken primarily in 1971/1972.

The main goal of being able to compare contemporary and retrospective models has proven quite successful. For example, Figure 13 presents two 3D modeled orthophotos depicting Omega House in its current state and as it was when first excavated, demonstrating how much similarity and variation can be seen between them. The exact location of walls and features that are no longer visible can easily be determined using the retrospective model while other features that have been removed can be accurately relocated during restoration. By adding crude Google Earth georeferencing to the Omega house retrospective model, the error was reduced from 53.443 pixels to 5.590 pixels for control points with a resolution of $4.01 \mathrm{~cm}$ per pixel. Adding measurements from the original site plan did allow measurement of the model but the poor resolution of the plan constituted considerable error in the measurements. Further work on the Omega House site is planned, with an accurate survey being done to provide georeferencing for points common to the current site and in the archival photographs. This will allow a measureable assessment of the archival modeling as well as increasing the accuracy of the models. 


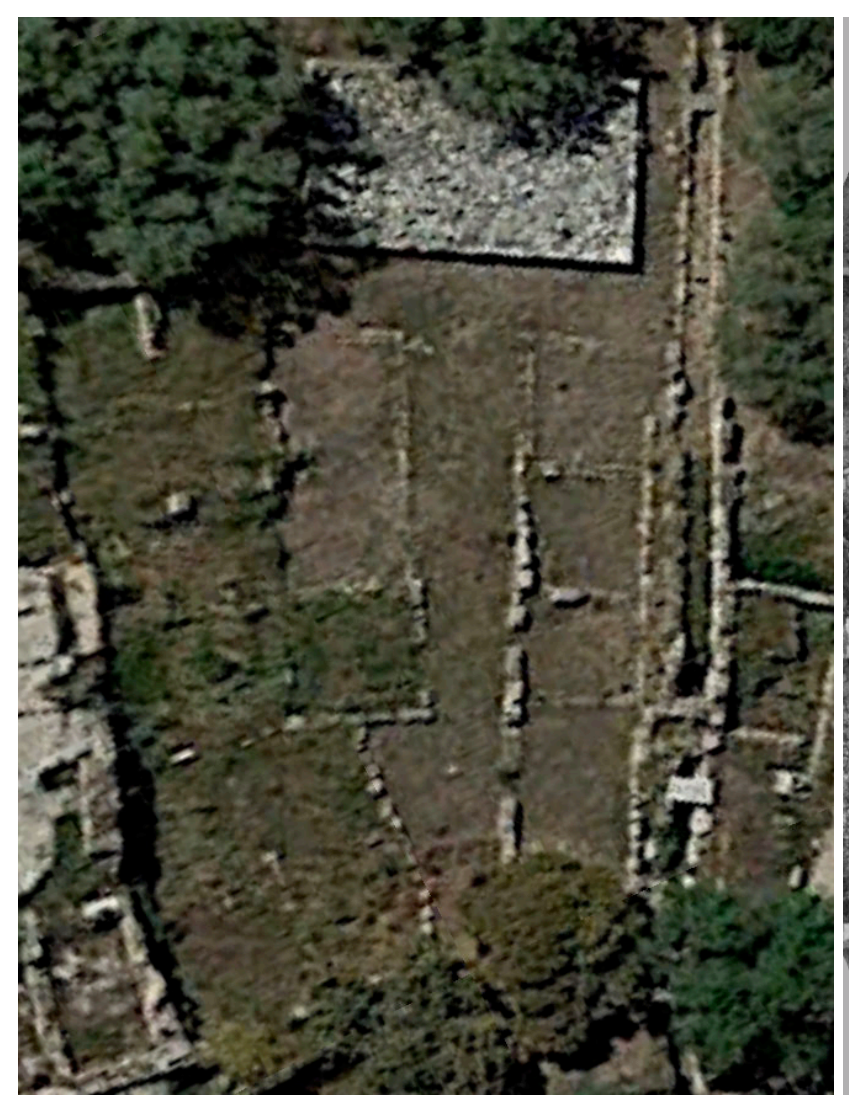

a)

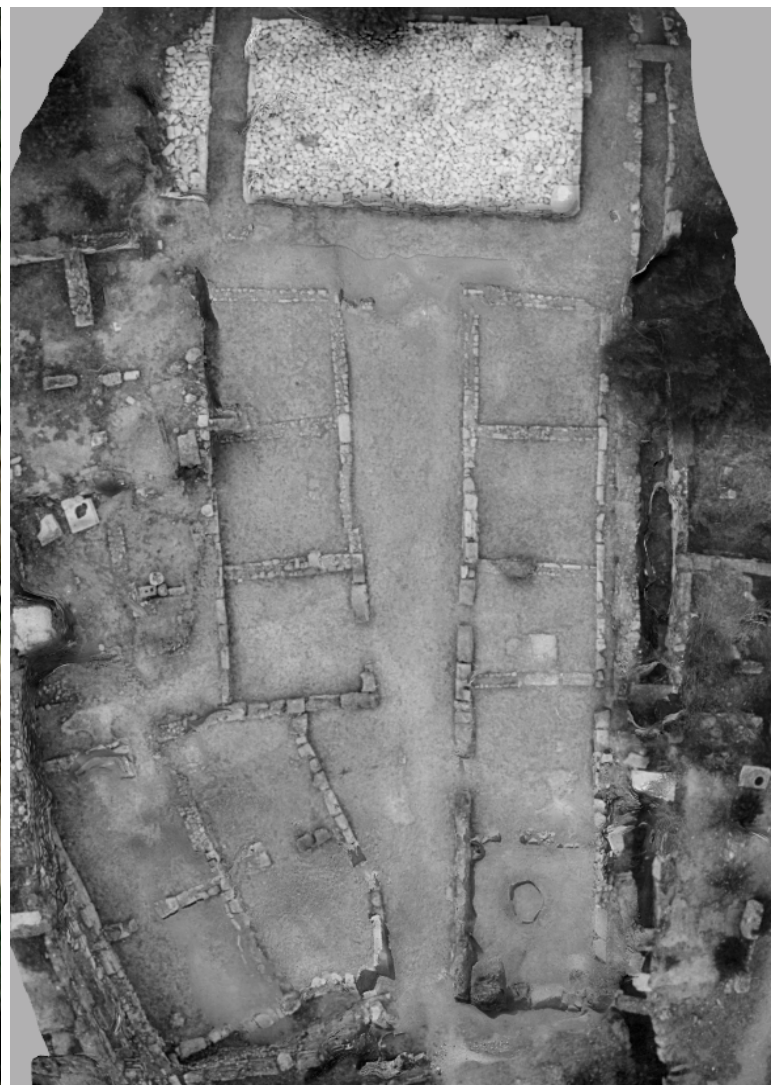

b)

Figure 14. State Prison: a) aerial photo of the Agora, 2016; b) 3D model of the same area, 1977.

The modern aerial photo and archival orthophoto (Figure 14) of the State Prison demonstrate not only how much backfilling has been done but also how much plant encroachment continues to take place. There were, however, enough common points currently uncovered by vegetation that by adding longitude and latitude from Google Earth to some of the retrospective points, measurements and metric accuracy could be reported. However, given that Google Earth itself has a margin of error [Mohammed et al. 2013] measured an average of about 1.8 meters of error in the Sudan region) it really is essential, where possible, to do a site survey of anything common to the current and past site in order to achieve true measurable results.

By removing questionable reference points, those with lower accuracy, too few common photos or points on photos that were vague, the accuracy of the measurements was improved considerably, with the total error in centimeters dropping from 43.5266 to 8.33943. 
1:622 C. Wallace

Table 1. Metric error in early georeferenced State Prison model.

\begin{tabular}{|c|c|c|c|c|c|}
\hline Label & X error $(\mathbf{c m})$ & Y error $(\mathbf{c m})$ & Z error $(\mathbf{c m})$ & Total (cm) & Image (pix) \\
\hline point 6 & 22.7583 & 23.1245 & 29.0152 & 32.4451 & 43.5266 \\
\hline point 2 & -7.38576 & -26.3025 & -24.8348 & 36.9207 & $5.067(12)$ \\
\hline point 4 & 37.4633 & -18.7778 & -12.9769 & 43.8692 & $1.154(7)$ \\
\hline point 5 & 2.9373 & -7.99362 & -40.7091 & 41.5904 & $1.759(12)$ \\
\hline point 6 & 1.47121 & 26.0867 & 47.24 & 53.9843 & $1.242(9)$ \\
\hline point 8 & -10.9094 & 26.8623 & -19.4049 & 34.8876 & $1.884(9)$ \\
\hline point 10 & 38.9845 & -26.4204 & -0.848297 & 47.1015 & $1.216(7)$ \\
\hline Total & 22.7583 & 23.1245 & 29.0152 & 43.5266 & 2.708 \\
\hline
\end{tabular}

Table 2. Later State Prison modeling results after removal of inaccurate points and photographs.

\begin{tabular}{|c|c|c|c|c|c|}
\hline Label & X error (cm) & Y error (cm) & Z error (cm) & Total (cm) & Image (pix) \\
\hline point 2 & -2.22667 & 2.89475 & 0.322468 & 3.66629 & $1.356(11)$ \\
\hline point 4 & 1.7488 & -3.61012 & -4.92709 & 6.35355 & $0.366(7)$ \\
\hline point 5 & -3.31309 & -7.84602 & -0.719496 & 8.54718 & $1.113(11)$ \\
\hline point 8 & 1.84448 & 11.9435 & 1.52432 & 12.1809 & $0.792(9)$ \\
\hline point 10 & -1.58133 & -6.87338 & 4.76965 & 8.51431 & $1.080(7)$ \\
\hline Total & 2.2314 & 7.38734 & 3.16136 & 8.33943 & 1.039 \\
\hline
\end{tabular}

Bringing together entire sites is difficult but possible. The less glamorous and yet equally desirable objective of remodeling small features within a site (Figure 15 and Figure 16), before and after, is very successful with reference points in Figure 15 (Omega House stairway) achieving an average accuracy of 0.264 pixels and those of Figure 16 (the Nymphaeum) reaching an average accuracy of 6.448 pixels. No accurate metrics were available for either model but, as mentioned above, further work with surveying is planned for 2017. 


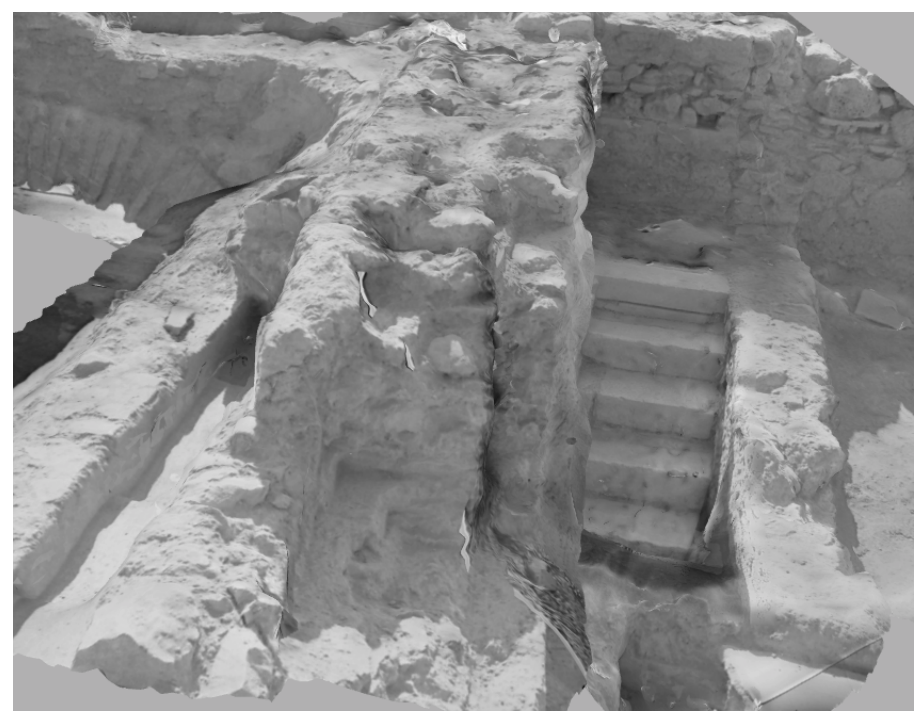

a)

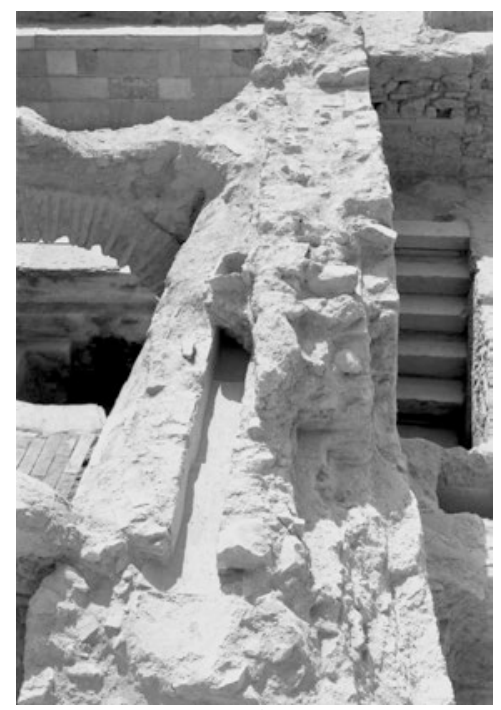

b)

Figure 15. 3D model of stairway in Omega House (a) and one of the archival photographs used (b). 


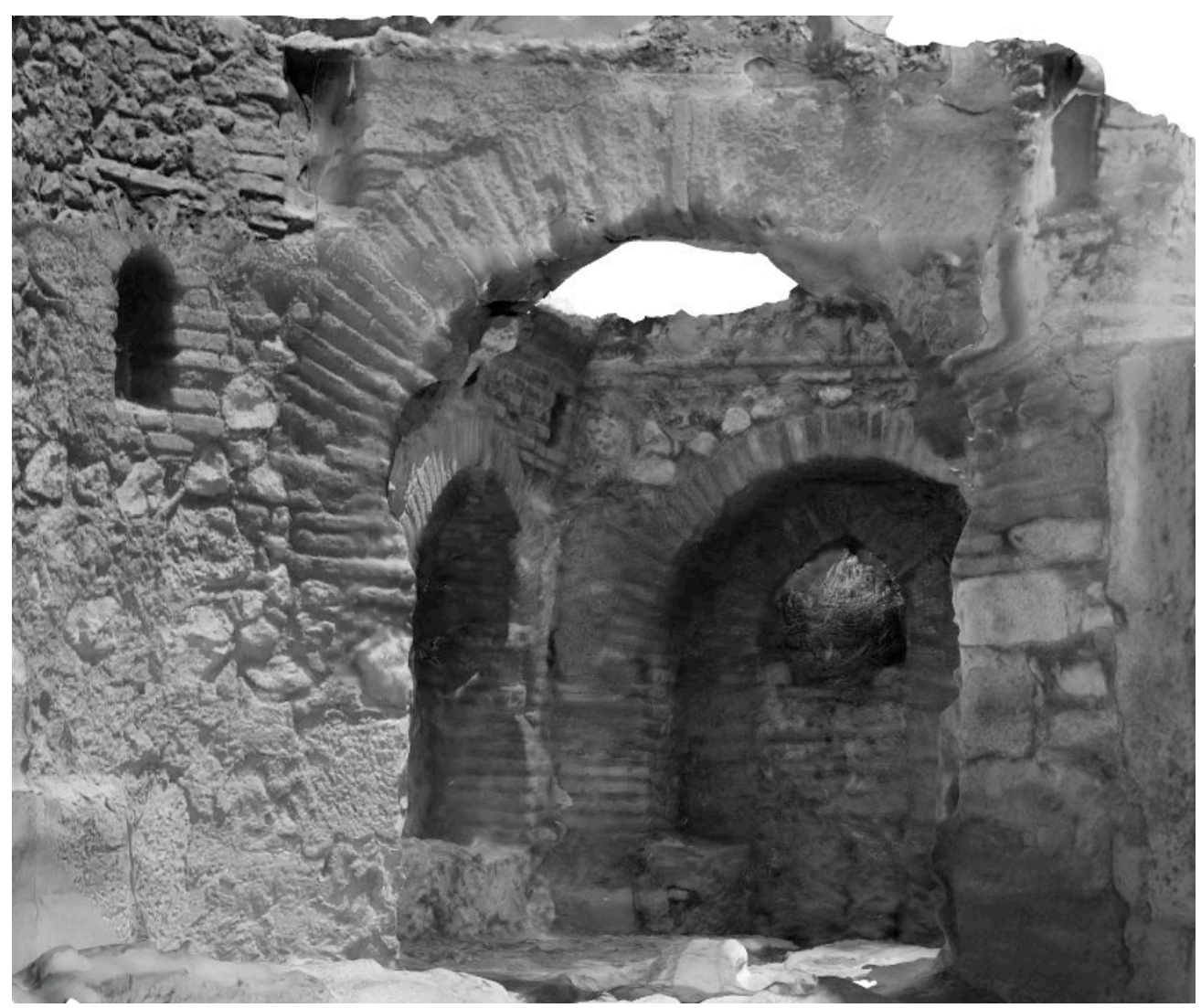

Figure 16. 3D model of Nymphaeum in Omega House.

\section{CONCLUSIONS}

Using new photographs to create models of the Fountain of Lamps allowed comparisons with the retrospective models for erosion and decay over the 45-year time span. These comparisons firmly impress the need for preservation and restoration. In order to gain accuracy in the contemporary and retrospective models, cleaning and surveying of the site is recommended. A previous cleaning of the site was quickly overgrown, due to an active water source and improper drainage by way of a gas driven pump. A more lasting solution will be clearing out the pool area and opening the original pool drain, which exits through an adjacent cliff face.

Similarly, Omega House has thorough archival photographic documentation and is an excellent candidate for retrospective photogrammetry. The goal is to produce the best possible 3D modeling based on archival materials as well as producing accurate contemporary models and using them comparatively in order to assess what level of restoration might be achieved in conjunction with conservation efforts so that a legitimate level of rebuilding (to its state in the early nineteen seventies) is made possible. 
In Summer 2017 further work has been conducted at Omega House, including the use of drones and accurate surveying and georeferencing. This data will be applied to the archival photographs to achieve the highest possible accuracy in order to facilitate restoration and conservations of the site. Other archives need to be examined and further possibilities explored.

While this technique is in its infancy, it shows enormous promise. Looking forward there is not only the possibility of creating measurable, accurate 3D models of sites as they once were but also, as a means of presenting them to the public on site and worldwide, in a virtual environment that gives the viewer a true sense of what they were once like.

\section{ACKNOWLEDGEMENTS}

The author gratefully acknowledges the contributions of The Hellenic Ministry of Culture and Sports, The American School of Classical Studies in Athens, John Camp, Bruce Hartzler, James Herbst, Maria Liaska, Dorina Moullou, Kleio Tsonga, Guy Sanders and James Wiseman.

All photographs in the Athenian Agora are courtesy of the Ephorate of Antiquities of AthensAthenian Agora Museum/ ASCSA archive and @Hellenic Ministry of Culture-Archaeological Receipts Fund.

\section{REFERENCES}

John M. Camp. 2003. The Athenian Agora; A Short Guide to the Excavations, American School of Classical Studies at Athens in collaboration with the Packard Humanities Institute.

Karen S. Garnett. 1975. Late Roman Corinthian Lamps from the Fountain of the Lamps. Hesperia:

The Journal of the American School of Classical Studies at Athens. 44, 2 (Apr. - Jun., 1975), 173-206. The American School of Classical Studies at Athens. Article Stable URL: http://www.jstor.org.proxy.lib.uwaterloo.ca/stable/147586

Peter L. Falkingham et al. 2014. Historical Photogrammetry: Bird's Paluxy River Dinosaur Chase Sequence Digitally Reconstructed as It Was prior to Excavation 70 Years Ago. PLOS ONE 9(4): e93247. doi: 10.1371/journal.pone.0093247

Laura Moore \& Gary Briggs. 2002. Long-term cliff retreat and erosion hotspots along the central shores of the Monterey Bay National Marine Sanctuary. Marine Geology 181,1-3 (15 March 2002), 265-283.

Athanasios Moysiadis \& Konstantinos Perakis. 2011. The Potential of Conventional Surveying, Photogrammetry and Laser Scanning in Monuments of Cultural Heritage Documentation. In Proceedings of the 3rd International CEMEPE \& SECOTOX Conference. Skiathos, June 19-24, 2011, 1291-1296.

Nagi Zomrawi Mohammed et al. 2013. Positional Accuracy Testing of Google Earth. International Journal of Multidisciplinary Sciences and Engineering 4, 6, (July 2013), Nagi Zomrawi Mohammed et al. 2013. Positional Accuracy Testing of Google Earth. International Journal of Multidisciplinary Sciences and Engineering 4, 6, 6-9

Dorina Moullou \& D. Mavromati. 2007. Topographic and photogrammetric recording of the Acropolis of Athens. Proc. Of XXI International CIPA Symposium. 1-6 October, Athens, Greece, 515-520. 
Colin Wallace. 2016. Photogrammetry in Mediterranean Archaeology. UWSpace. http://hdl.handle.net/10012/10344

Rachel Opitz \& W. Fred Limp. 2015. Recent Developments in High-Density Survey and Measurement (HDSM) for Archaeology: Implications for Practice and Theory. Annual Review of Anthropology, 44 (2015),347-64.

Dominic Powlesland. 2014. 3Di - enhancing the record, extending the returns, 3D imaging from free range photography and its application during excavation. In Hans Kamermans et al., eds. The Three Dimensions of Archaeology (Proceedings of the XVII UISPP World Congress, 1-7 September 2014, Burgos, Spain. Volume 7. Oxford: Archaeopress, 13-32.

Received October 2016; revised September 2017; accepted November 2017. 